\title{
RESEARCH-IN-BRIEF
}

\section{Issue entropy in the Internet age}

Changes in issue entropy in Germany between 1994 and 2005

Themen-Entropie im Internetzeitalter

Veränderungen in der Themen-Entropie in Deutschland

zwischen 1994 und 2005

Volker Gehrau \& Gianna Haake 
Volker Gehrau, Institut für Kommunikationswissenschaft, Westfälische Wilhems-Universität Münster, Bispinghof 9-14, 48143 Münster; Kontakt: gehrau(at)uni-muenster.de

Gianna Haake, Institut für Kommunikationswissenschaft, Westfälische Wilhems-Universität Münster, Bispinghof 9-14, 48143 Münster; Kontakt: gianna.haake(at)uni-muenster.de 


\title{
RESEARCH-IN-BRIEF
}

\section{Issue entropy in the Internet age \\ Changes in issue entropy in Germany between 1994 and 2005}

\author{
Themen-Entropie im Internetzeitalter \\ Veränderungen in der Themen-Entropie in Deutschland zwischen \\ 1994 und 2005
}

\section{Volker Gehrau \& Gianna Haake}

\begin{abstract}
The aim of this paper is to analyze the impact of the diffusion of the Internet on audience fragmentation in Germany. Fragmentation is defined in terms of a declining probability that an individual will find like-minded others who are concerned about the same issues as that individual. Accordingly, fragmentation increases if the number of issues the individual is concerned about (nominal issue diversity) declines and the entropy of issues at the level of society (issue entropy) increases. The paper provides a brief review of publications concerned with media, fragmentation, and issue entropy. It then picks up a recent study, which revealed no relevant changes in nominal issue diversity in Germany during the period of Internet diffusion. In a second step, survey data representative for the German population during the same time period is analyzed to test for an increase in issue entropy. The findings reveal a small but systematic trend of growing issue entropy. This trend could not be attributed to the diffusion of the Internet. First, it was not possible to do so because age groups that had different rates of Internet adoption demonstrated a lack of differences in issue entropy. Second, there are differences between the dynamics of issue entropy and the dynamics pertaining to the diffusion of the Internet as entropy decreased after 2000, whereas the diffusion of the Internet continued to increase rapidly. It is therefore concluded that the diffusion of the Internet did not cause issue fragmentation during the sample period from 1994 to 2005.
\end{abstract}

Keywords: Issue entropy, diversity, fragmentation, Internet, diffusion.

Zusammenfassung: Ziel des Beitrags ist es, den Effekt der Verbreitung des Internets auf die Fragmentierung der Gesellschaft zu untersuchen. Fragmentierung wird dabei als abnehmende Wahrscheinlichkeit dafür definiert, auf Personen mit denselben Themeninteressen zu treffen. Danach steigt die Fragmentierung, wenn die Anzahl der Themen, für die sich die einzelne Person interessiert, abnimmt und die Themen-Entropie auf Gesellschaftsebene zunimmt. Der Beitrag bietet zunächst einen Überblick von Studien zu Medien, Fragmentierung und Themen-Entropie. Ferner werden publizierte Ergebnisse einer Studie referiert, nach der in Zeit der Diffusion des Internets in die deutsche Bevölkerung kein systematischer Anstieg der individuellen Anzahl interessierender Themen stattgefunden hat. Im zweiten Schritt werden repräsentative Umfragedaten der deutschen Bevölkerung desselben Zeitraums präsentiert, um den Anstieg der Themen-Entropie zu untersuchen. Die Ergebnisse zeigen zwar einen systematischen Anstieg der Themen-Entropie; dieser Trend konnte 
aber nicht auf die Diffusion des Internets zurückgeführt werden. Zum einen variierte die Themen-Entropie nicht systematisch zwischen Gruppen unterschiedlich starker Internetnutzung. Zum anderen entsprach die Entwicklung der Themen-Entropie nicht der Diffusionskurve, da die Themen-Entropie nach 2000 leicht abnahm, wohingegen die Diffusion des Internets stark voranschritt. Insofern legen die Daten nahe, dass die Diffusion des Internets nicht systematisch zur Fragmentierung der Gesellschaft beigetragen hat.

Schlagwörter: Themen-Entropie, Vielfalt, Fragmentierung, Internet, Diffusion.

\section{Diversity and fragmentation in modern societies}

Mass media have an important societal role that is paradoxical in some respects. On the one hand, mass media are supposed to provide information to citizens about the variety of social and cultural phenomena and matters. Accordingly, mass media are supposed to offer and inspire diversity. On the other hand, mass media are supposed to stimulate consensus about the most important problems in a society. This function is linked to the agenda-setting hypothesis, which presumes that everyone is concerned about a relatively small number of issues, namely those that are most salient in mass media coverage. According to this notion, diversity is reduced in favor of big issues. It is possible that this second function is being threatened by a more general trend toward fragmentation in modern societies. According to Takeshita (2005), the diffusion of new media outlets - especially the Internet could be expected to provide a new dynamic to agenda-setting, and he proposed the study of agenda-setting effects in conjunction with diversity effects in order to understand the fundamental development of fragmentation. Gehrau (2013) pursued this perspective by considering issue diversity as a means of establishing an ana- lytical link between the agenda-setting function of mass media and the fragmentation of social interests. For this purpose, he defined fragmentation in terms of a declining probability that an individual will find like-minded others who are concerned about the same issues as that individual. High fragmentation is associated with a low probability of finding like-minded others, and low fragmentation is characterized by a high probability of finding likeminded others (Gehrau, 2013, p. 134). In addition, Gehrau (2013, p. 135) operationalized this probability as a function of two different indicators of diversity: nominal diversity and entropy. Nominal issue diversity represents the individual perspective in that it measures the number of issues the individual names as the most important problems facing the country. Issue entropy, on the other hand, is concerned with the societal level in that it relates to the analysis of the overall heterogeneity of issues that are named as important problems. If these two diversity measures are used in conjunction with each other, it follows that fragmentation will be high (or increasing) when nominal diversity is low (or decreasing) and entropy is high (or increasing). In this case, the individual is only concerned about one or two issues while a large number of issues are on the pub- 
lic agenda of society. By contrast, the probability of finding like-minded others will be greater (and fragmentation lower) when the individual is concerned about a greater number of issues while society as a whole is concerned about a smaller number of issues. Accordingly, fragmentation will be low (or decreasing) when nominal issue diversity is high (or increasing) and issue entropy is low (or decreasing). Finally, Gehrau (2013) used the trends revealed by diversity indicators during the years in which the diffusion of the Internet predominantly took place and a comparison between age groups - as a proxy for Internet use to analyze the impact of the Internet on fragmentation. His results revealed no evidence for a decline in nominal issue diversity or for an increase in single-issue publics during the specified period of Internet diffusion in Germany. Although it was possible to identify periods in which Internet diffusion and nominal issue diversity developed in parallel, the differences between age groups did not support the hypothesis that such developments might be caused by expanded Internet use (Gehrau, 2013, pp. 136-141). However, strictly speaking, these results cannot be attributed to fragmentation because the research only took into account nominal issue diversity and did not take issue entropy into consideration.

The present study is a follow-up of the SCM publication by Gehrau (2013) on nominal issue diversity. It picks up the idea of issue fragmentation as a function of nominal issue diversity and issue entropy from the previous study, adds the results for issue entropy that have been calculated by using the same dataset as in the previ- ous study, and summarizes both studies with a view to assessing the impact of the Internet on diversity and fragmentation at the level of society. ${ }^{1}$

\subsection{Fragmentation}

As Gehrau (2013) observed, the majority of studies on fragmentation have focused on the fragmentation of publics (e.g., Tewksbury, 2005; Webster, 2009; Webster \& Ksiazek, 2012). Researchers have predicted the emergence of segmentation (Gitlin, 1998) and "public sphericules" (Katz, 1996). It has been established that the Internet has made a specific contribution to the evolution of these phenomena by making it possible for users to find sufficient information on specialized issues online, whereas such information was not available in earlier forms of mass media (e.g., Althaus \& Tewksbury, 2002; Takeshita, 2005). While traditional media are determined by journalistic selection procedures, the Internet potentially offers information on any topic users might be looking for and thereby enables them to create their individual media agendas. However, a democratic society cannot operate efficiently without some level of consensus because its capacity to deal with several issues at a time is limited. The assumption underlying the link between fragmentation and the agenda-setting hypothesis in this study is

1 The study on nominal issue diversity was published in 2013 (Gehrau, 2013) as a basis for the Issues of the Millennium research project. Its results formed the basis for the further analysis of aggregation in agenda-setting research. Only after the data had been extensively adjusted and recoded with a view to addressing other research questions did it also become possible to assess issue entropy. 
that traditional media have an integrating effect and produce consensus, whereas the Internet tends to lead to fragmentation. This hypothesis was previously tested by Coleman and McCombs (2007) as part of research in which age groups were used as an indicator of Internet affinity. However, they found that Internet usage did not have an effect in terms of any relevant differences between the age groups, a finding which could be attributed to the redundancy in the agendas of different media outlets.

Nevertheless, agenda-setting effects are not the only possible indicator of fragmentation. Gehrau (2013) observed a link between diversity and fragmentation with regard to earlier studies (e.g., Takeshita, 2005; DiMaggio, Hargittai, Neumann, and Robinson, 2001; Neuman, 1991; Chaffee and Metzger, 2001). The general idea pertaining to this observation is that differentiation between media outlets and a rise in the number of media outlets are sources of fragmentation. In addition to decreasing agenda-setting effects of traditional mass media, therefore, an increase in issue diversity was also used as an indicator of fragmentation in most studies (e.g., Schönbach et al., 2005).

\subsection{Issue entropy}

Diversity studies which analyze nominal diversity or thematic diversity take place either at the individual level or at the aggregated level (for similar, see Reinemann \& Brosius, 1998, pp. 274275). Nominal diversity measures the number of issues each respondent names as important (see Gehrau, 2013, for a recent review of nominal diversi- ty studies). In contrast, entropy is an indicator of the thematic heterogeneity of issues. Entropy indicators are concerned with regional populations during defined periods. Such indicators make it possible to compare them across regions or periods. Measurements such as the number of different issues named by the members of the relevant population or the share of members who name the most widespread issues have been used as such indicators in previous studies. Yet, both of these measurements are problematic because the values depend heavily on how issues are categorized and especially on the number of issue categories, which means that it is only possible to compare results based on the same set of issues. For this reason, most studies use the $\mathrm{H}$ statistic developed by Shannon and Weaver (1949), a standardized measure of disorder, which is referred to as entropy. A high level of disorder implies a high level of diversity and is associated with entropy values approximating one, whereas the entropy values approximate zero in the case of a low level of disorder and a low level of diversity.

In a seminal diversity study by Chaffee and Wilson (1977), issue entropy was analyzed on the basis of the $\mathrm{H}$ statistic. The researchers compared the entropy of issues that were named in different US counties and found greater issue diversity in media-rich counties than in media-poor counties in the 1970s. Approximately ten years later, Lasorsa (1988) replicated the study and found greater entropy in counties with high SES, counties with high social variety, and counties with competitive newspapers. The first analysis of changes over time in the USA was undertaken by McCombs and 
Zhu (1995), who examined changes in issue carrying capacity (nominal diversity), issue volatility, and issue entropy. The results revealed a curvilinear increase in carrying capacity between the 1950s and the mid-1970s, which was followed by a decrease up to 1994 , as well as a continuous increase in issue volatility. Most interestingly from the point of view of the present study, they revealed a systematic increase in issue entropy in the USA between 1970 and 1994. The estimated beta of the whole period was .35 . A study by Tan and Weaver (2013), which was based on the measurement of the distribution across various issues, revealed that agenda diversity decreased in the USA between the 1950s and the 1980s, which was followed by an increase up to 2004. Reinemann and Brosius (1998) analyzed 30 German surveys from the beginning of 1990 to the end of 1992. The level of diversity was very high in Germany during this period and, in the long run, did not demonstrate a general trend. However, in the short run, the level of diversity varied significantly according to current events. At the individual level, the answers were more diverse in the cases of people who often watched TV, people who were older, and people who had lower levels of formal education. Peter and de Vreese (2003) used the number of thematically different issues that respondents named in a survey to compare thematic diversity in five European countries. They found that the highest level of diversity was in Germany, where the number of TV outlets used and interest in politics correlated positively with diversity, whereas a negative correlation was identified with respect to the amount of TV use. The correlation of diversity with the number of TV outlets used occurred in four out of five countries and was the most systematic effect. De Waal and Schönbach (2008) used a similar approach in the Netherlands and found that reading the print version of a newspaper had a positive effect on individual diversity but they did not identify any such effect in the case of reading the online newspaper. Gehrau and Goertz (2010) identified a growth in the diversity of media issues that were picked up on in interpersonal communication in Germany between 1997 and 2007; they also established that a notable share of those media issues was communicated via the Internet in 2007.

Two findings of this brief research review ought to be kept in mind. Firstly, issue entropy in a society seems to be enhanced by a diverse media diet: Entropy is higher in regions with competing newspapers (Chaffee \& Wilson, 1977; Lasorsa, 1988) and increases as a result of using different TV outlets (Peter \& de Vreese, 2003). Secondly, from the 1970s onward, issue entropy in modern societies appears to increase slowly but systematically (McCombs \& Zhu, 1995).

\section{Hypotheses}

Following Takeshita (2005) and Gehrau (2013), we expected that the diffusion of the Internet would cause an increase in issue diversity because of the growing accessibility and diversity of information offered by this new medium. At the macro level, we made the assumption that issue diversity would be lower in the years in which the Internet was not widely diffused within modern society than in the years in which the Internet was widely diffused within modern so- 
ciety. Two indicators of issue diversity were taken into account: the entropy of issues and the number of prevalent issues. Accordingly, the following two hypotheses were tested:

H1: Issue entropy grew during the years in which the diffusion of the Internet predominantly took place.

H2: The number of prevalent issues (those mentioned by at least ten percent of the people) declined during the years in which the diffusion of the Internet predominantly took place.

If changes in issue diversity over time were a result of the diffusion of the Internet, it would be expected that they would have been faster and greater in those groups in which Internet use is typically high, which particularly applies to young people, than in groups in which Internet use is typically low, which particularly applies to older people. Consequently, the following two additional hypotheses were examined:

H3: The growth of issue entropy over time was faster and more pronounced for young people than for older people.

H4: The decline in prevalent issues (those mentioned by at least ten percent of the people) over time was faster and more pronounced for young people than for older people.

\section{Method}

\subsection{Data}

Our data were derived from the secondary analysis of a representative German survey conducted by the German public opinion and market research institute FORSA. For the survey,
500 telephone interviews were carried out each working day. Since the beginning of 1994, these interviews had included a question about the most important problems (MIP) in Germany, and the MIP question was asked until the end of 2005. The data were recently reprocessed and made available for scientific use. The survey was based on a probability sample, which was obtained by means of an independent random digit dialing procedure. This produced a vast dataset on an almost daily basis for twelve years $(n=1.4$ million). The dataset was aggregated to the level of weeks to remove the gaps caused by weekends and holidays and to allow time series analysis. This resulted in a sample of 626 consecutive weeks. To make the general trends predicted by our hypotheses visible for this 12-year period, the data were aggregated to the level of years in keeping with the approach taken in the previous study on nominal issue diversity.

\subsection{Dependent variables}

The issues on the public agenda were measured as most important problems (MIP). As part of this approach, the MIP question was phrased in regard to three problems: 'Which are the three most important problems in Germany at the moment?' As some people named more than three, up to ten different problems were coded by the interviewer. The issues coded by FORSA were subsequently recoded in accordance with the coding scheme of the German Longitudinal Election Study (GLES), which had proved to be very reliable and applicable to the survey data. $99.7 \%$ of the list of problems could be subsumed under the categories of the 
GLES coding scheme ${ }^{2}$. The GLES scheme consists of multiple levels of categories. For the diversity analysis, the 14 categories from the top level, which comprise politics, polity, and twelve policy topics, and the 95 categories from the second level were used. The 95 narrow categories from the second level are subordinate to the 14 broad categories from the first level. By comparing both ways of coding, we were able to control for differences produced by different ways of defining issues and different ways of calculating diversity measures.

Following Gehrau (2013, p. 134), fragmentation was conceptualized in terms of a declining probability that an individual will find like-minded others who are concerned about the same issues as that individual. To assess this probability, two different indicators were taken into account: entropy and the number of prevalent issues. Entropy was measured according to the $\mathrm{H}$ statistic developed by Shannon and Weaver (1949), which we considered to be a proven and appropriate measure of the entropy of the public agenda (Chaffee \& Wilson, 1977; McCombs \& Zhu, 1995). It depends on the number of issues as well as their relative frequencies. When we used a coding scheme with only 14 categories, we found that answers were provided in each category most of the time and entropy could be interpreted in this case as mainly just representing a measure of the distribution of answers among these categories. Nevertheless, where the values of $\mathrm{H}$ are based on the same

2 To guarantee reliability and comparability, the matching of FORSA and GLES categories was checked by the authors of the GLES coding scheme. number of categories, they are easy to compare because the range of possible values of $\mathrm{H}$ does not change. In addition, the measurements based on the 95 categories were compared with those based on the 14 categories. For an even better understanding, the values of both kinds of measurement were standardized to a value between zero and one, where "zero" indicated the dominance of one issue only and "one" indicated an even distribution of answers among all categories. In keeping with this approach, entropy was calculated by using the formula

$$
\mathrm{H}=\frac{\sum_{i}^{k} P_{i}\left(\ln P_{i}\right)}{\sum_{i}^{k} \frac{P}{k}\left(\ln \frac{P_{k}}{k}\right)}
$$

where $\mathrm{P}_{\mathrm{i}}$ is the percentage of people naming an issue as one of the most important ones and $\mathrm{P}_{\mathrm{k}}$ is the percentage of people who would have to name a given issue if the distribution among all (14/95) issues were equal. The standardized entropy measure is less dependent on nominal diversity than non-standardized entropy measures. Entropy based on the 14 broad issue categories was expected to be higher than in the case of the 95 narrow subcategories. This is because the process of aggregating meant that, in the case of the 14 categories, sub-issues with a high share of mentions and those with a low share of mentions might be grouped together, which would cause the distribution across the 14 categories to be more uniform. It is to be noted that the probability of finding likeminded others is inversely related to entropy.

In contrast, the number of prevalent issues is positively related to the probability of finding like-minded others. This diversity indicator counts the mean number of issues that at least ten 
percent of the interviewees mentioned as one of the most important problems in Germany in the space of one week. This measure was established by McCombs and Zhu (1995), who, following Neuman (1990), defined the cut-off point at which an issue captures public attention as 10 percent.

\subsection{Independent variables}

Although the main question about fragmentation caused by new media concerns the impact of the Internet, our data did not include questions about media use. Therefore, it was not possible to test the hypothesis directly by comparing issue diversity among Internet users and non-Internet users. However, the date of the interview was used as the independent variable and served as a proxy for effects caused by the diffusion of the Internet into society. Consequently, the two diversity measures were correlated with the year in which the interview was conducted. In 1994, most Germans were not familiar with the Internet. At the end of the 1990s, the majority of Germans were still not using the Internet but diffusion was expanding at a high rate. From 2004 onward, more than half of the German population had access to the Internet and diffusion had slowed down substantially ${ }^{3}$ (Figures 1 and 2; Table 1 within the appendix).

To substantiate the results, age was used as a second independent variable and a further proxy for Internet use, an approach that had previously been successfully used by Coleman and McCombs (2007). The Internet was

3 ARD-Onlinestudie (1997-2006), see http:// www.ard-zdf-onlinestudie.de (see also Eimeren \& Frees, 2010) adopted much more quickly by the group of younger Germans than by older Germans. Every tenth young German aged between 14 and 19 had access to the Internet in 1997 and half of them had access to the Internet in 2001. In 2006, more than 90 percent of young Germans used the Internet at least occasionally. By contrast, the percentage of Internet users among people aged 60 and above did not pass 10 percent until 2003 and rose from zero to 20 percent throughout the entire time span (Figure $3 \mathrm{a} / \mathrm{b}$; Table 1 ). It was therefore expected that changes in diversity related to the diffusion of the Internet would develop more quickly in the group of younger people than in the case of older people.

\section{Results}

\subsection{Issue diversity in Germany from 1994 to 2005}

Hypothesis 1 postulated a growth in issue entropy between 1994 and 2005 owing to the diffusion of the Internet.

With respect to broad issues (based on 14 issue categories) and with respect to sub-issues (based on 95 issue categories), both graphs show a decline in entropy between 1995 and 1996, a growth in entropy between 1997 and 2000 , and a small but continuous decline from 2000 to 2005 . The entropy measured on the basis of the broad issue categories was slightly higher. By approximating a linear function over time, it was possible to establish that entropy with respect to the broad issue categories was nearly stable over the specified period but entropy with respect to the sub-issue categories followed a linear growth trend, as anticipated in H1. It is possible that this 
Figure 1: Mean entropy per week for the years 1994 to 2005

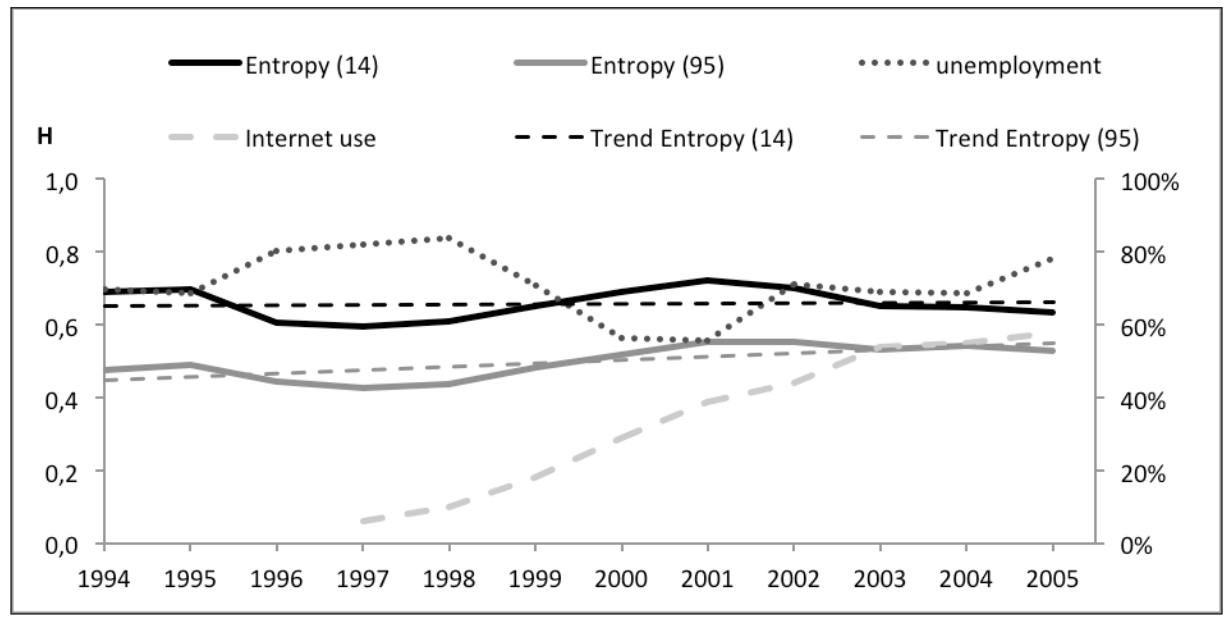

trend could be interpreted as an effect of the Internet. However, entropy and Internet diffusion both increased from 1997 to 2000, yet entropy decreased after 2000, whereas the diffusion of the Internet continued to increase rapidly until at least 2003 (Figure 1; Table 1).

Our data revealed another interesting correlation, which seems to offer a better explanation for the changes in entropy. The share of people who mentioned "unemployment" as one of the most important problems was high in the years between 1995 and 1997, when entropy was low, and declined from 1997 to 2000, when entropy values increased. Afterwards, both graphs continued to move in opposite directions as the share of people who mentioned "unemployment" as one of the most important problems grew. Because entropy, from a mathematical perspective, always reflects the dominance of issues, it will decrease if a major issue, such as unemployment, becomes more prominent. This result illustrates the importance of the issue of unemployment during the specified period as well as its impact on diversity.
If it is assumed that the salience of unemployment was not driven by the Internet, it can be said that the diffusion of the Internet - for which the years of the interviews serve as a proxy - might at best have had a minor impact on the growth of entropy (Figure 1; Table 1).

The picture changed when the 'prevalent issues', which were mentioned by ten percent or more of the respondents in the space of one week, were considered. The distribution in this case also seemed to be influenced by the share of people who mentioned unemployment; however, it was not influenced as strongly as the entropy measures. In contrast to the entropy measures, a linear trend could even be identified in the case of the broad issue categories in this respect; this trend was yet more pronounced in the case of the 95 subissue categories. The number of broad issues with a share of more than ten percent declined from six and a quarter in 1994 to five in 2005. For sub-issues, this figure fell by an even greater margin with a decline from six and a half to four and a half during the same period. Once again, it was not possible 
Figure 2: Mean number of issues over 10\% per week for the years 1994 to 2005

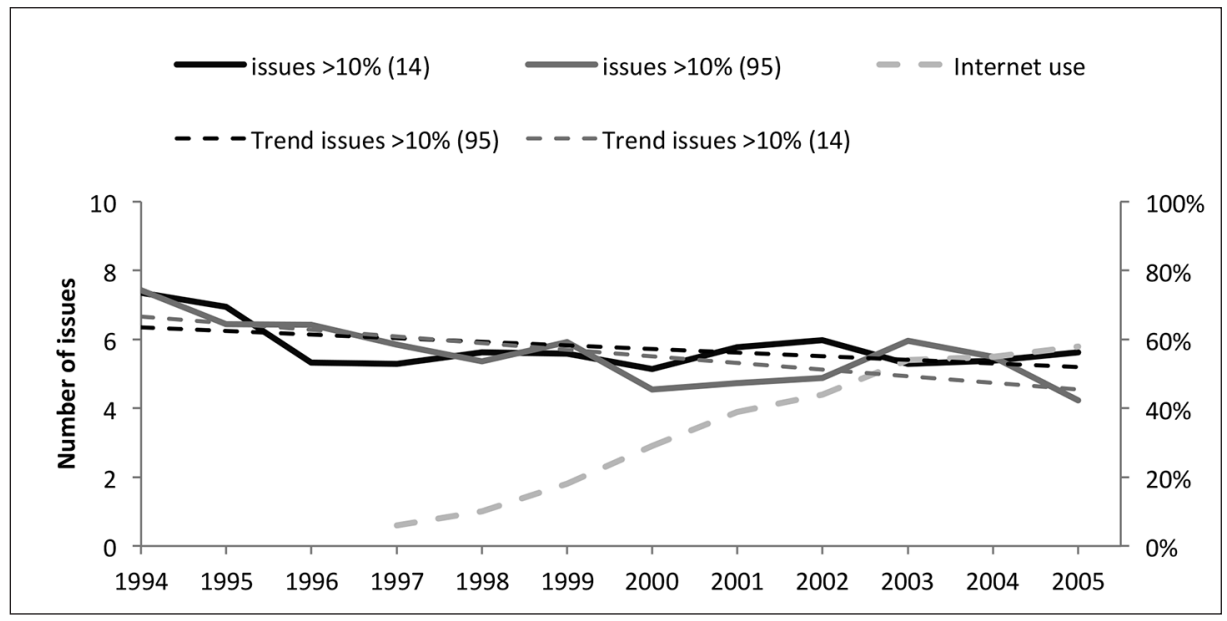

to interpret this development as an effect of Internet usage. This is because the main decline in big issues occurred between 1994 and 1999, whereas the diffusion of the Internet predominantly took place after that period at a time when the number of prevalent issues in Germany had, on average, ceased to exhibit a significant decrease (Figure 2; Table 1).

\subsection{Difference in the development of issue diversity between young and older Germans}

The third and fourth hypothesis examined differences between age groups. Because the Internet diffused quickly into the younger segments of German society, it was expected that the growth of issue diversity would have been faster and more pronounced in the group of people aged below 20 than among those aged 60 and above. Because the diffusion of the Internet got significantly under way in 1998, it was expected that effects caused by Internet usage would be similar for both groups until 1998 and then demonstrate a rapid change in the case of the teenagers until 2003 and only a very slow change with respect to the cohort of those aged 60 and above.

The entropy values for the broad issue categories did not follow the pattern of the diffusion of the Internet as none of the two distributions for the age groups demonstrated a linear trend over time (Figure 3a; Table 1). If the very slight decline in entropy with respect to older people is taken into account, it is apparent that the data even contradicts hypothesis 3 . The entropy values for the sub-issue categories painted a different picture. Both distributions followed a linear trend over time, which indicated a growth from approximately 0.45 in 1994 to 0.55 in 2005. However, the entropy measures did not correlate with the diffusion of the Internet and, contrary to the expectations pertaining to $\mathrm{H} 3$, the entropy values did not differ between age groups (Figure 3b; Table 1).

Once again, the picture changed when the number of issues mentioned by at least ten percent of the interviewees was considered. In the case of the 14 
Figure 3a: Mean entropy (14 issue categories) and Internet use among young and old

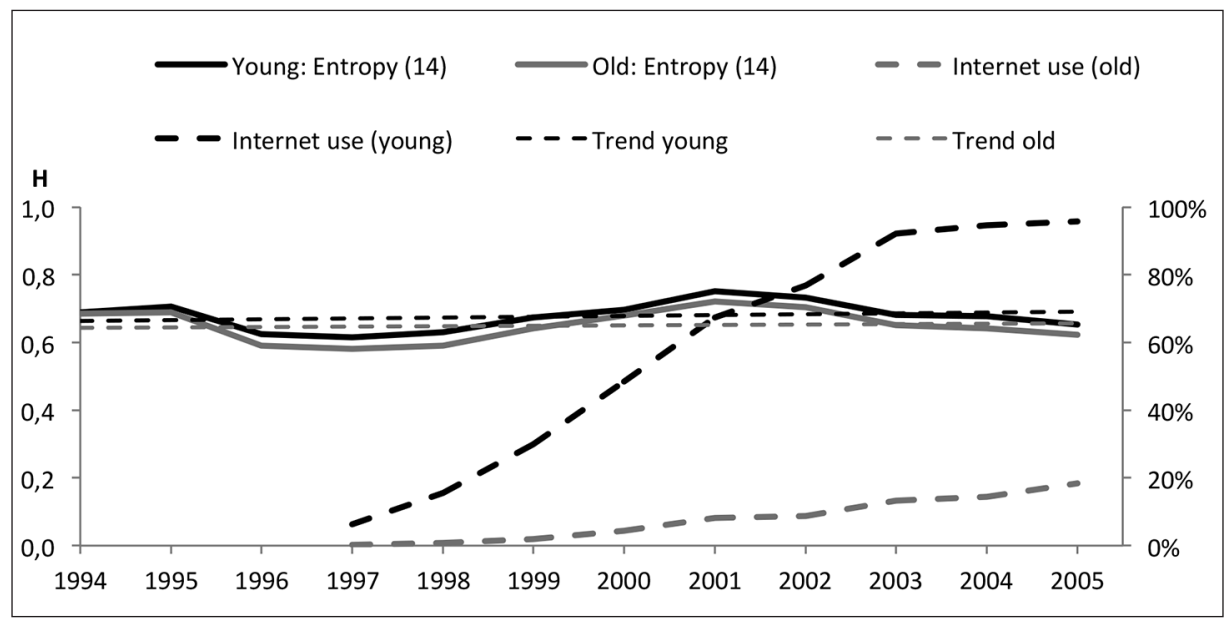

Figure 3 b: Mean entropy (95 issue categories) among young and old

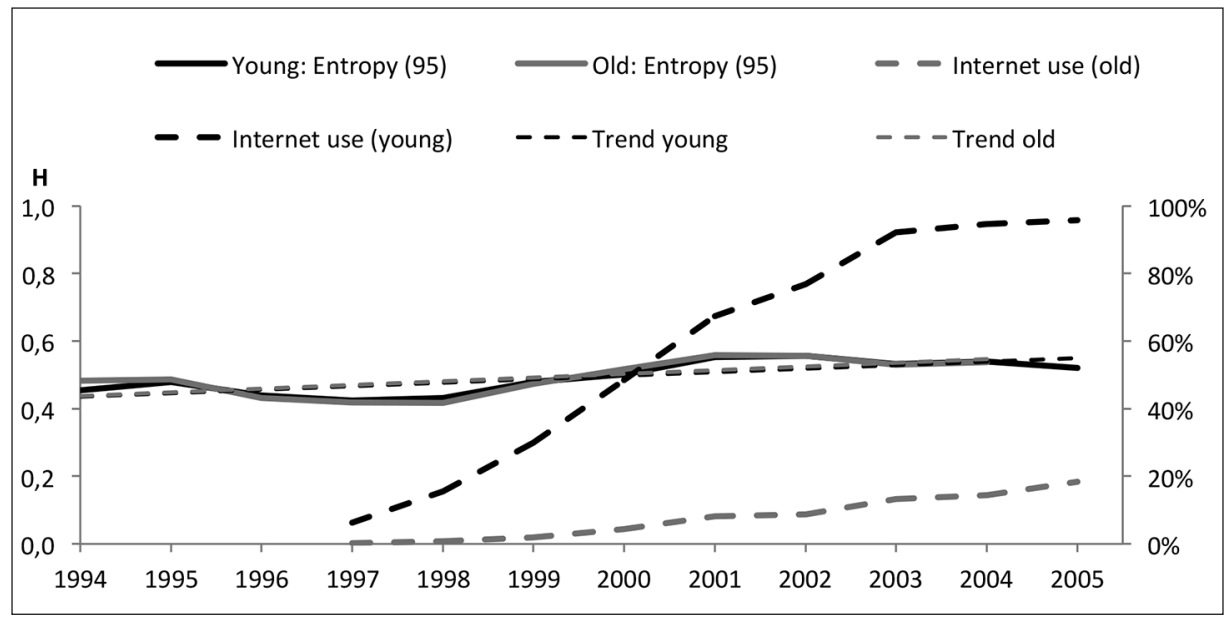

broad issue categories, the number of these prevalent issues was approximately one higher in the teenager group than in the case of older people; the only exception was the year 2002, when the value in both groups was equally low. This might have been because other big issues may have been excluded from the agenda in the aftermath of $9 / 11$. In addition, a linear trend was identified in both groups between 1994 and 2005
(Figure 4a; Table 1). In the case of both groups, the average number of prevalent issues fell by approximately one issue. By taking into account the 95 subissue categories, it was possible to gain a different overall impression. The number of prevalent issues appeared to follow a curvilinear trend for the older generations; it decreased between 1994 and 2000 and increased in the subsequent years. Consequently, it was not 
Figure 4a: Mean number of issues over 10\% (14 issue categories) among young and old

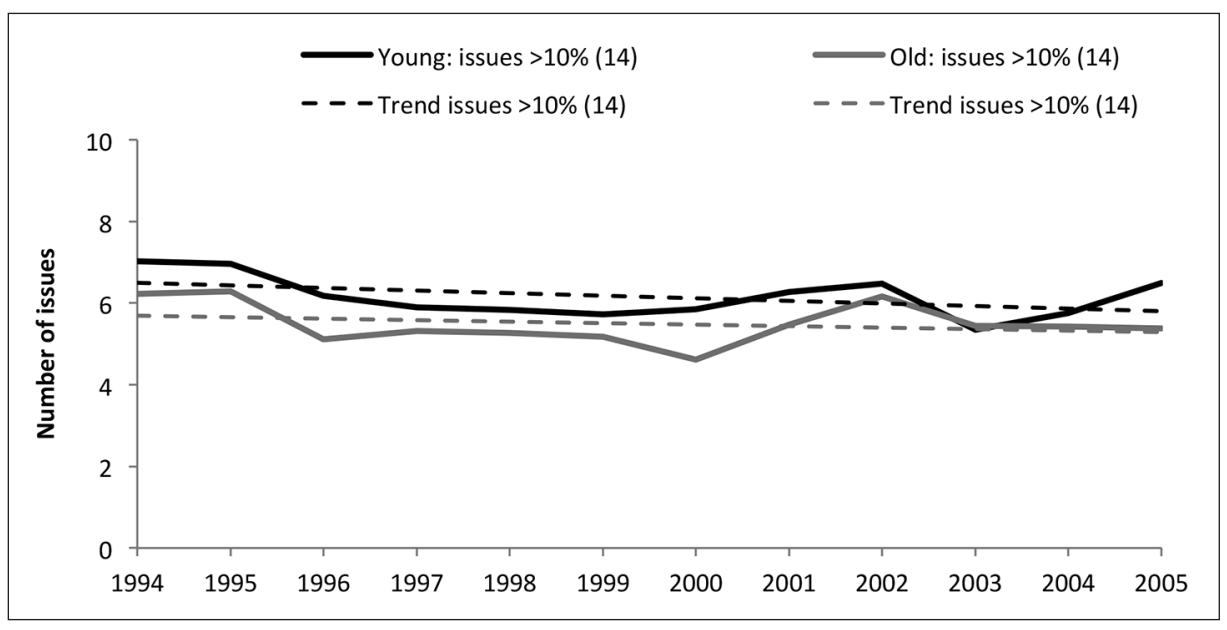

Figure 4b: Mean number of issues over 10\% (95 issue categories) among young and old

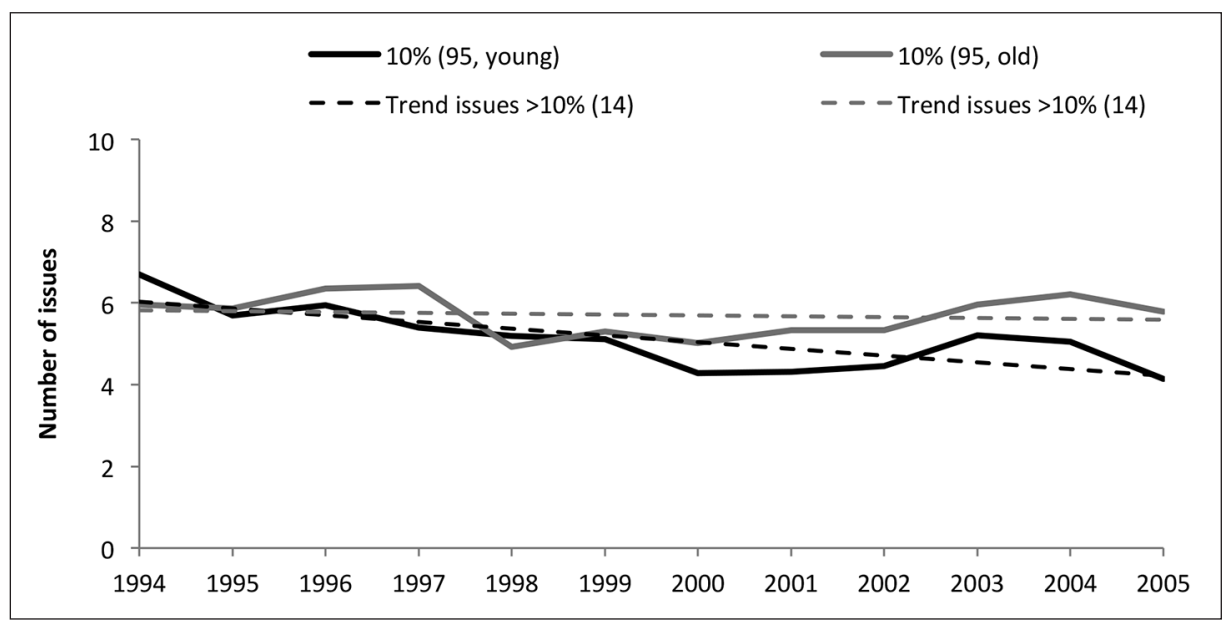

possible to approximate a linear trend. By contrast, the distribution over time in the teenager group varied from year to year, it decreased on average from approximately six issues in 1994 to nearly four issues in 2005 and, in so doing, exhibited a strong linear trend. Furthermore, in contrast to the results for the 14 broad issue categories, the number of prevalent issues in the case of the
95 sub-issue categories was higher and more stable over time for the older cohort than for the younger cohort (Figure $4 \mathrm{~b}$; Table 1 ).

\section{Discussion}

Gehrau (2013) did not find a trend of declining nominal issue diversity in Germany between 1994 and 2005; he 
Figure 5: Development in nominal issue diversity and issue entropy

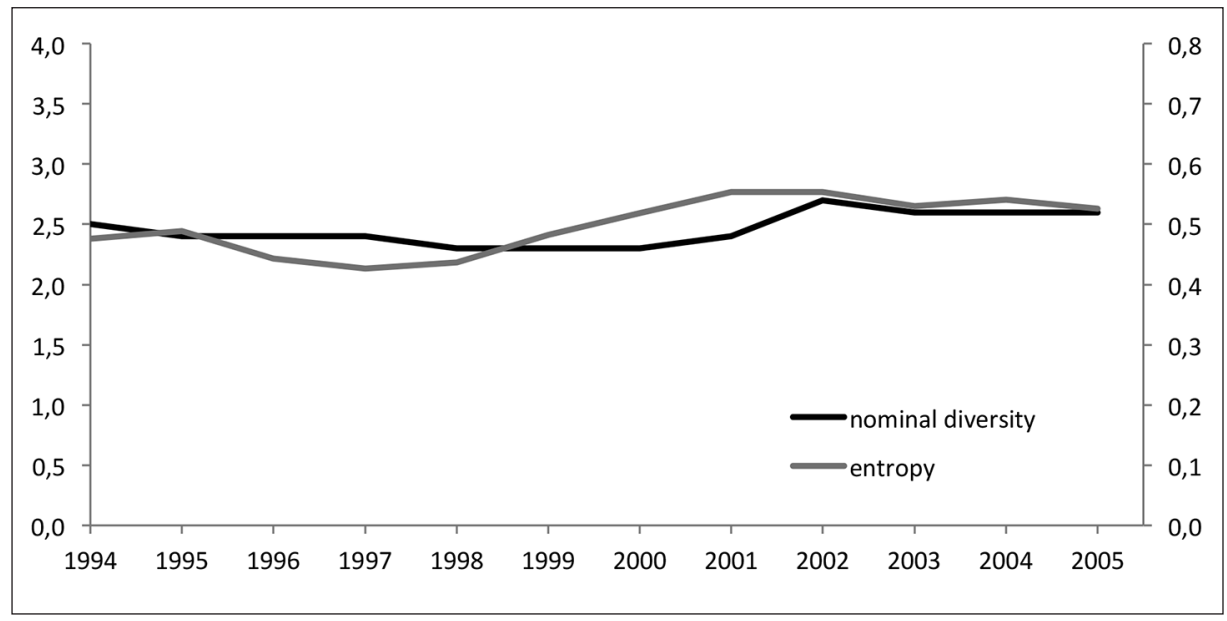

also did not find an increase in the number of people who considered only one issue to be important. Similarly, the present study did not reveal evidence to support the notion that the diffusion of the Internet into German society systematically boosted issue entropy. The way in which fragmentation in society was conceptualized in the present study established an inverse link between nominal issue diversity and issue entropy. By analyzing both developments in detail, it was possible to identify a balance between nominal diversity and entropy between 1994 and 1995 and between 2002 and 2005. Even though this balance was at a slightly higher level in the latter period, this did not have a bearing on fragmentation because the distance between the two graphs remained the same and therefore indicated that the effects of nominal diversity and entropy cancelled each other out. A similar instance of effects cancelling each other out was also identified in the middle period in which entropy initially decreased, then increased, and finally decreased again, whereas nominal diver- sity reacted inversely. This meant that the chance that an individual would have found like-minded others concerned about the same issues as that individual did not change during the period of the diffusion of the Internet (Figure 5).

Nevertheless, systematic changes in diversity were identified in the data. The entropy calculated on the basis of the 95 sub-issue categories slightly increased from 1994 to 2005 with respect to all respondents as well as with respect to the youngest and oldest cohort. In addition, the number of prevalent issues declined moderately between 1994 and 2005; this also applied to all respondents as well as to both age groups. At first glance, it might appear that these results support the hypotheses. However, on closer inspection, there are good arguments to suggest that it would appear impossible to attribute these tendencies to the diffusion of Internet usage. McCombs and Zhu (1995) identified a trend of increasing diversity (entropy) from 1954 to 1994 in the USA, which appeared to represent a general trend in 
society. It might be that this trend simply continued in Germany. Moreover, this development in diversity did not reflect the diffusion of the Internet, and differences between the age groups, which were expected to result from the dramatic differences between these groups in terms of the diffusion of Internet usage, did not occur.

The overall trend of increasing entropy corresponds to the trend in public agenda diversity that was identified in the study by Tan and Weaver, which indicated a decrease in public agenda diversity from 1954 to 1980 and an increase between 1980 and 2004 in the USA. The authors of that study attributed the latter increase in public agenda diversity to media deregulation in the case of the cable industry and to the launch of CNN as a news-oriented TV network (Tan \& Weaver, 2013, p. 784). There are good reasons to assume that the deregulation of the German media system in the mid-1980s, especially in light of the emergence of private TV and radio stations with different specializations broadcasting to millions of Germans, had a similar effect on diversity in Germany. Moreover, although the Internet might have offered additional information in relation to individual concerns and interests during the timeframe of this study, it might not have offered much additional information in relation to the political and societal issues that the MIP question was asking about.

In summary, the data does not provide evidence to suggest that the diffusion of the Internet caused issue entropy to increase in Germany. Consequently, if these results are considered in conjunction with the results obtained for nominal issue diversity (Gehrau 2013), it can be concluded that the diffusion of
Internet usage did not cause fragmentation, where fragmentation is defined in terms of a declining probability that an individual will find like-minded others who are concerned about the same issues as that individual. In regard to the present study, two limitations ought to be kept in mind. Firstly, the present study was based on argumentation relating to the level of aggregated data and did not measure Internet usage at the individual level. This means that the effects identified could have been caused by other factors linked to developments that took place in Germany between 1994 and 2005 or that they might have been caused by other factors associated with the analyzed age groups. Secondly, the period analyzed in this study takes into account effects produced by the Internet 1.0. It was not possible to assess effects that might be caused by the Internet 2.0, especially those produced by social networks, because the Internet 2.0 was created and diffused after 2005.

\section{References}

Allen, R. L., \& Izcaray, F. (1988). Nominal agenda diversity in a media-rich, lessdeveloped society. Communication Research, 15(1), 29-50.

Althaus, S. L., \& Tewksbury, D. (2002). Agenda setting and the 'new' news Patterns of issue importance among readers of the paper and online versions of the New York Times. Communication Research, 29(2), 180-207.

Anderson, C. (2006). The long tail: Why the future of business is selling less of more. New York: Hyperion.

Chaffee, S. H., \& Metzger, M. J. (2001). The end of mass communication? Mass Communication and Society, 4(4), 365379. 
Chaffee, S. H., \& Wilson, D. G. (1977). Media rich, media poor: Two studies of diversity in agenda-holding. Journalism Quarterly, 54(3), 466-476.

Coleman, R., \& McCombs, M. E. (2007). The young and agenda-less? Exploring age-related differences in agenda setting on the youngest generation, baby boomers, and the civic generation. Journalism and Mass Communication Quarterly, 84(3), 495-508.

Culbertson, H. M., Evarts, D., Richard, P. B., Sandell, K., \& Stempel, G. H. III. (1994). Media use, attention to media and agenda richness. Newspaper Research Journal, 15(1), 14-29.

DiMaggio, P., Hargittai, E., Neumann, W. R., \& Robinson. J. P. (2001). Social implications of the Internet. Annual Review of Sociology, 27, 307-336.

van Eimeren, B., \& Frees, B. (2010). Fast 50 Millionen Deutsche online - Multimedia für alle? Ergebnisse der ARD/ ZDF-Onlinestudie 2010. Media Perspektiven, 13, 334-349.

Gitlin, T. (1998). Public sphere or public sphericules? In T. Liebes \& J. Curran (Eds.), Media, ritual and identity (pp. 168-174). London: Routledge.

Gehrau, V., \& Goertz, L. (2010). Gespräche über Medien unter veränderten medialen Bedingungen. Publizistik, 55(2), 153-172.

Gehrau, V. (2013). Issue diversity in the Internet age. Changes in nominal issue diversity in Germany between 1994 and 2005. Studies in Communication I Media, 2(1), 129-142.

Katz, E. (1996). And deliver us from segmentation. Annals of the American Academy of Political and Social Science, 546, 22-33.

Lasorsa, D. L. (1991). Effects of newspaper competition on public opinion diversity. Journalism Quarterly, 68(1-2), 38-47.
McCombs, M., \& Shaw, D. (1972). The agenda-setting function of mass media. Public Opinion Quarterly, 36, 176187.

McCombs, M. E., \& Zhu, J.-H. (1995). Capacity, diversity, and volatility of the public agenda. Trends from 1954 to 1994. Public Opinion Quarterly, 59(4), 495-525.

Neuman, W. R. (1991). The future of the mass audience. New York: Cambridge University Press.

Peter, J., \& de Vreese, C. H. (2003). Agenda-rich, agenda-poor: A cross-national comparative investigation of nominal and thematic public agenda diversity. International Journal of Public Opinion Research, 15(1), 45-64.

Reinemann, C., \& Brosius, H.-B. (1998). Themenvielfalt in der Bevölkerungsagenda Ost- und Westdeutschlands. Publizistik, 43(3), 273-286.

Rogers, E. M. (2003). Diffusion of innovations (5th ed.). New York: Free Press.

Schönbach, K., de Waal, E., \& Lauf, E. (2005). Online and print newspapers. Their impact on the extent of the perceived public agenda. European Journal of Communication, 20(2), 245-258.

Shannon, C. E., \& Weaver, W. (1949). The mathematical theory of communication. London, New York: University of Illinois Press.

Takeshita, T. (2005). Current critical problems in agenda-setting research. International Journal of Public Opinion Research, 18(3), 275-296.

Tan, Y., \& Weaver, D. H. (2013). Agenda diversity and agenda setting from 1956 to 2004 . What are the trends over time? Journalism Studies, 14(6), 733-789.

Tewksbury, D. (2005). The seeds of audience fragmentation: Specialization in the use of online news sites. Journal of Broadcasting and Electronic Media, 49(3), 332-348. 
de Waal, E., \& Schönbach, K. (2008). Presentation style and beyond: How print newspapers and online news expand awareness of public affairs issues. Mass Communication and Society, 11(2), 161-176.

Wanta, W., King, P.-T., \& McCombs, M. E. (1995). A comparison of factors influencing issue diversity in the U.S. and Taiwan. International Journal of Public Opinion Research, 7(4), 353-365.
Webster, J. G. (2005). Beneath the veneer of fragmentation: Television audience polarization in a multichannel world. Journal of Communication, 55(2), 231-252. Webster, J. G., \& Ksiazek, T. B. (2012). The dynamics of audience fragmentation: Public attention in an age of digital media. Journal of Communication, 62(1), $39-56$. 
Table 1: Entropy indicators and unemployment as important issue by age group between 1995 and 2005

\begin{tabular}{|c|c|c|c|c|c|c|c|c|c|c|c|c|}
\hline & 1994 & 1995 & 1996 & 1997 & 1998 & 1999 & 2000 & 2001 & 2002 & 2003 & 2004 & 2005 \\
\hline entropy $(14$, all $)$ & 0.69 & 0.69 & 0.59 & 0.58 & 0.59 & 0.64 & 0.68 & 0.72 & 0.70 & 0.65 & 0.64 & 0.62 \\
\hline entropy (14, young: 14-19) & 0.69 & 0.71 & 0.62 & 0.61 & 0.63 & 0.67 & 0.70 & 0.75 & 0.73 & 0.68 & 0.68 & 0.65 \\
\hline entropy $(14$, old: $60+)$ & 0.69 & 0.69 & 0.59 & 0.58 & 0.59 & 0.64 & 0.68 & 0.72 & 0.70 & 0.65 & 0.64 & 0.62 \\
\hline entropy $(95$, all $)$ & 0.48 & 0.49 & 0.44 & 0.43 & 0.44 & 0.48 & 0.52 & 0.55 & 0.55 & 0.53 & 0.54 & 0.53 \\
\hline entropy (95, young: 14-19) & 0.45 & 0.48 & 0.44 & 0.42 & 0.43 & 0.48 & 0.50 & 0.55 & 0.56 & 0.53 & 0.54 & 0.52 \\
\hline entropy $(95$, old: $60+)$ & 0.48 & 0.49 & 0.43 & 0.42 & 0.42 & 0.47 & 0.52 & 0.56 & 0.56 & 0.53 & 0.54 & 0.52 \\
\hline issues over $10 \%(14$, all $)$ & 7.35 & 6.94 & 5.33 & 5.29 & 5.62 & 5.60 & 5.13 & 5.77 & 5.98 & 5.29 & 5.38 & 5.62 \\
\hline big issues (14, young: 14-19) & 7.02 & 6.96 & 6.18 & 5.90 & 5.83 & 5.73 & 5.85 & 6.27 & 6.47 & 5.35 & 5.75 & 6.50 \\
\hline big issues (14, old: $60+)$ & 6.23 & 6.29 & 5.12 & 5.31 & 5.27 & 5.17 & 4.62 & 5.47 & 6.16 & 5.44 & 5.43 & 5.38 \\
\hline issues over $10 \%(95$, all $)$ & 7.42 & 6.44 & 6.42 & 5.85 & 5.36 & 5.92 & 4.54 & 4.73 & 4.88 & 5.96 & 5.49 & 4.23 \\
\hline big issues (95, young: 14-19) & 6.69 & 5.69 & 5.94 & 5.39 & 5.19 & 5.12 & 4.29 & 4.31 & 4.45 & 5.21 & 5.06 & 4.13 \\
\hline big issues (95, old: $60+)$ & 5.96 & 5.87 & 6.35 & 6.41 & 4.92 & 5.31 & 5.02 & 5.33 & 5.33 & 5.96 & 6.21 & 5.79 \\
\hline unemployment (all) & 0.70 & 0.69 & 0.80 & 0.82 & 0.84 & 0.71 & 0.56 & 0.56 & 0.71 & 0.69 & 0.69 & 0.78 \\
\hline unemployment (young: 14-19) & 0.67 & 0.65 & 0.77 & 0.79 & 0.83 & 0.67 & 0.53 & 0.48 & 0.64 & 0.67 & 0.67 & 0.76 \\
\hline unemployment (old: 60+) & 0.67 & 0.65 & 0.78 & 0.77 & 0.80 & 0.66 & 0.49 & 0.52 & 0.70 & 0.67 & 0.66 & 0.78 \\
\hline Internet use (all) & & & & $6.5 \%$ & $10.4 \%$ & $17.1 \%$ & $28.6 \%$ & $38.8 \%$ & $44.1 \%$ & $53.5 \%$ & $55.3 \%$ & $57.9 \%$ \\
\hline Internet use (young: 14-19) & & & & $6.3 \%$ & $15.6 \%$ & $30.0 \%$ & $48.5 \%$ & $67.4 \%$ & $76.9 \%$ & $92.1 \%$ & $94.7 \%$ & $95.7 \%$ \\
\hline Internet use (old: 60+) & & & & $0.2 \%$ & $0.8 \%$ & $1.9 \%$ & $4.4 \%$ & $8.1 \%$ & $8.7 \%$ & $13.3 \%$ & $14.5 \%$ & $18.4 \%$ \\
\hline
\end{tabular}

